\title{
Research of Surfacing Technology and Performance on Round Steel
}

\author{
XU Kai ${ }^{* 1}$, HAN Bing-yin², ZHANG Shu-quan ${ }^{3}$
}

\section{(1. Department of Mechanical Engineering, Anhui Technical College of Mechanical and Electrical Engineering, Wuhu 241000,China; 2. Anhui Conch Kawasaki Energy Conservation Equipment Manufacturing Co., Ltd., Wuhu 241000, China; 3. Chinese Academy of Institute of Plasma Physics, Hefei 230000, China)}

Key words: overlaying welding technology; microstructure; hardness; bending property Abstract: Using semi automatic manual flux cored welding methods, selection of $\Phi 2.8$ (V-100Mo) cored wire for overlaying welding in $36(\mathrm{Q} 235 \mathrm{~B})$ steel substrate with different welding processes for multi-layer welding experiment. The deposited metal microstructure and mechanical properties of welding rod are analyzed. The hardness and bending strength of deposited metal are investigated. The results show that the hardness of the deposited layers depends on the microstructure. After welding, bending strength improved significantly by using heat preservation and slow cold. Finally the reasonable welding process which has high hardness and good bending performance is determined.

\section{Introduction}

Surfacing welding is a process to overlay the material with certain properties on the surface of workpieces $^{[1]}$. Poor surfacing process can significantly reduce products' property as well, which can't not only satisfy the requirements of normal operation of equipment, but also reduce productivity, increase production cost and even cause safety accidents, which is against the industrial development requirements of our country as "energy reservation and consumption reduction" and "safe development". Therefore, it becomes especially important to develop reasonable surfacing welding process. Good surfacing welding methods will not only significantly increase life of the workpiece, but also save manufacture and maintenance cost, shorten maintenance and replacing time and reduce cost of closing down at the same time. In this test, Ф2.8 (V-100Mo) powder-cored wire is adopted to produce multi-layer molten metal on $\Phi 36(\mathrm{Q} 235 \mathrm{~B})$ round steel material to research reasonable surfacing welding process.

\section{Test material and process}

\subsection{Test material and preparation before welding}

Q235B round steel is chosen as the base metal with size of $\Phi 36 \mathrm{~mm} \times 1000 \mathrm{~mm}$. Before test, the surface of the base metal is cleaned to remove the oxide skin, greasy dirt and make the surface without any flaw (crack, gas hole, sand hole, puff, etc.)

The wire in the test is V-100Mo surfacing welding wire with size of $\Phi 2.8 \mathrm{~mm}$. The wires must maintain dry before test.

\subsection{Welding process}

Manual semi-automatic surfacing welding, which is widely used at present, is adopted in the test. DCEP (Direct Current Electrode Positive) is chosen to carry out the welding under different current and insulation measures. The welding parameters are shown in table 1. Three layers are welded on the matrix surface to ensure the thickness of the deposited metal to over $6 \mathrm{~mm}$. The welding sketch is shown as fig. 1. So the outermost layer can best reflect the property of the wire. The specimen must be cooled down in air or insulation cotton after welding of one layer before doing the next layer in order to ensure certain interlayer-temperature. The test specimen corresponding to different welding process is marked with A or B, respectively.

\footnotetext{
*Brief introduction to the author: Xu Kai(1974.6-), male, master of engineering, associate professor. Main
} direction studied: welding technology. E-mail:ahjdxukai@126.com, Tel: 18298269028 
Tab.1 Process parameters of over-laying welding

\begin{tabular}{|c|c|c|c|c|c|c|c|c|c|c|}
\hline \multicolumn{4}{|c|}{ Base metal: $\Phi 36 \times 1000(\mathrm{Q} 235 \mathrm{~B})$} & \multicolumn{2}{|r|}{ wire: $\Phi 2.8$} & \multicolumn{2}{|c|}{ V-100Mo } & \multicolumn{3}{|c|}{$\begin{array}{l}\text { Welding method: bright arc, horizontal } \\
\text { welding, three layer }\end{array}$} \\
\hline specimen & 1syer & $\begin{array}{l}\text { current } \\
\text { I/A }\end{array}$ & $\begin{array}{l}\text { Voltage } \\
\text { U/V }\end{array}$ & $\begin{array}{c}\begin{array}{c}\text { Welding } \\
\text { speed }\end{array} \\
\mathrm{mm} / \mathrm{s}\end{array}$ & $\begin{array}{c}\text { heat } \\
\text { input } \\
\mathrm{KJ} / \mathrm{cm}\end{array}$ & $\begin{array}{c}\text { Preheat } \\
{ }^{\circ} \mathrm{C}\end{array}$ & $\begin{array}{l}\text { extension } \\
\mathrm{mm}\end{array}$ & $\begin{array}{c}\text { interlayer } \\
\text { temperature }{ }^{\circ} \mathrm{C}\end{array}$ & $\begin{array}{c}\text { weld } \\
\text { height } \\
\mathrm{mm}\end{array}$ & remark \\
\hline \multirow{3}{*}{ A } & 1 & 280 & 28 & 4 & 19.6 & & & 1 & $1-2$ & \multirow{3}{*}{ air-cooling } \\
\hline & 2 & 290 & 29 & 5 & 16.82 & I & 25 & $\leq 150$ & $2-3$ & \\
\hline & 3 & 300 & 30 & 5 & 18 & & & $\leq 150$ & $2-3$ & \\
\hline \multirow{3}{*}{ B } & 1 & 320 & 30 & 4 & 24 & 200 & \multirow{3}{*}{25} & I & $1-2$ & \multirow{3}{*}{$\begin{array}{l}\text { cooling } \\
\text { with } \\
\text { asbestos } \\
\text { insulation }\end{array}$} \\
\hline & 2 & 340 & 32 & 5.5 & 19.78 & I & & $\leq 250$ & $2-3$ & \\
\hline & 3 & 350 & 34 & 6 & 19.83 & I & & $\leq 250$ & $2-3$ & \\
\hline
\end{tabular}

\section{Microstructure and performance test analysis}

\subsection{Microstructure analysis}

Fig. 2 presents the microstructure of the matrix material - round steel. Wherein, the grey massive polyhedron structure is ferrite while the black massive polyhedron structure is pearlite. Ferrite and pearlite are distributed uniformly.

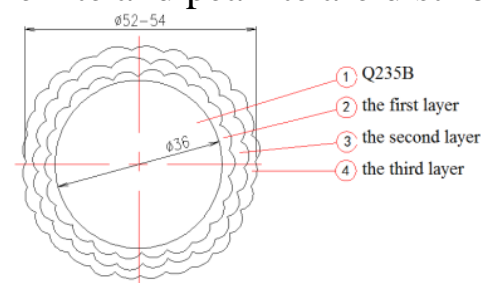

Fig.1 The diagram of over-laying test welding in round steel

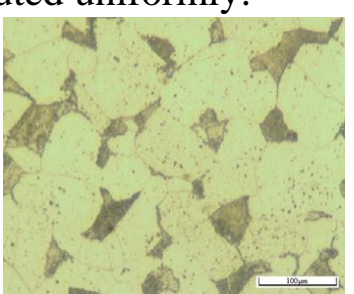

Fig.2 The microstructure of base metal

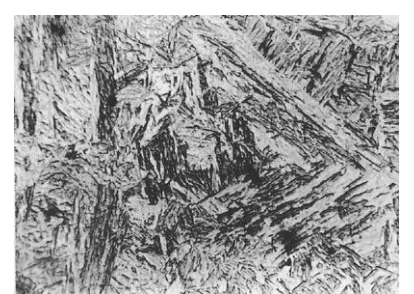

Fig.3 The microstructure of test Fig.4 The microstructure of specimen A $500 x$

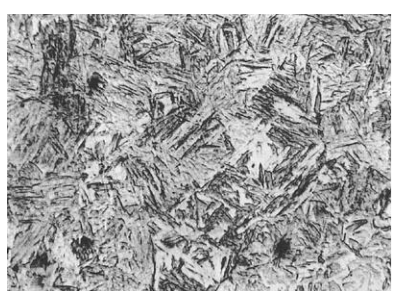
specimen B500x

Fig. 3 presents the microstructure of the welding layer on specimen A after cooling to ambient temperature in air. Wherein, the black bulk is martensite while the uniformly distributed white net structure is residual austenite dendrites. There is also a little bit bainite particle. Different structures are distributed uniformly.

Fig. 4 presents the microstructure of the welding layer in specimen B after cooling to ambient temperature in insulation cotton. It mainly includes white self-tempering martensite, residual austenite and black bainite. Martensite is flocculent and there is also white self-tempering martensite ${ }^{[2]}$. Compared with the last figure, the bainite crystal grain in this figure has bigger size. And generally this layer is more uniformed. By comparing the welding layer produced by different currents we find that the microstructure of the deposited metal is obviously different from the microstructure of the matrix material. It is transformed from ferrite + perlite to martensite. Although the powder-cored wire has big penetration ratio and high dilution rate ${ }^{[3]}$, its temperature increase rate is big and its standing time at high temperature is short, in which the ferrite can't fully spread out after being melted and form residual austenite distributed in the deposited metal. But after comparing with metallographic microstructure, we find the content of residual austenite in specimen A is significantly higher than that in specimen B. Although affected by the base metal, there is still martensite structure in the first layer. Through welding layer by layer, influence of base metal to the deposited metal is further reduced, which is better proved by the deposited metal structure in test specimen B, where martensite is transformed to needle shape and further flocculent. Meanwhile, from the microstructure of the deposited metals in the two specimens, we also find that there is much martensite in both specimens. The main reason is that the alloy metal Cr, Mo and V in the wire decreases the transformation temperature of martensite, which increases the stability of undercooled austenite as well as the hardenability, and its cooling rate is improved after welding. All of these features said above provide conditions for the formation of martensite. In the meantime, through comparing the microstructure of the deposited metal we also find that the martensite in specimen $\mathrm{B}$ is finer and distributed more uniformly, which improves the hardness and also 
improves the wear resistance of the deposited metal by certain degree.

\subsection{Hardness test and analysis}

Actually the change of hardness reflects the change of the microstructure. The area with high hardness is good at strength and wear resistance. But there is no one-to-one correspondence between the wear resistance and hardness, while the wear resistance of the metal is related to the type and distribution of the microstructure. In the test, we test the hardness by the direction from the deposited metal to the base metal by making two points on each layer. As shown by table 2, Rockwell hardness tester is used to measure the hardness of the points of specimen A and B and the relation between the testing area and the hardness.

Tab.2 The corresponding relationship between the hardness and test area of the test specimen A and B

\begin{tabular}{cccc}
\hline test zone & test point & hardness of specimen A (HRC) & hardness of specimen B (HRC) \\
\hline Surfacing of the first layer & 3 & $38,46 、 42$ & $46 、 45 、 47$ \\
Surfacing of the second layer & 3 & $58,56 、 60$ & $62 、 61,62$ \\
Surfacing of the third layer & 3 & $51,50 、 49$ & $51,52 、 49$ \\
\hline
\end{tabular}

As shown in table 2, we can know hardness of the deposited metal in specimen $\mathrm{A}$ is about 51HRC and minimum $38 \mathrm{HRC}$ while $52 \mathrm{HRC}$ for specimen $\mathrm{B}$ with minimum $45 \mathrm{HRC}$ and maximum $62 \mathrm{HRC}$, namely average hardness of the deposited metal in specimen B is higher than specimen A. We used the same wires for welding of the two specimens. So the hardness of the deposited metal in the two specimens are almost the same. But the welding heat input of deposited metal in specimen B is bigger than A. So average hardness of the deposited metal of specimen B is a little higher than $\mathrm{A}$ and the minimum hardness is also obviously higher while using the same wires. The main reason of such results is that when we use small welding current that the welding energy input is decreased and the standing time at high temperature is short. Some alloy metal elements with high melting points can't full spread in the molten bath and fail to realize the alloying function. Therefore, there is dendrite grain formed, which is with low hardness. But on the other hand, when we use high current, surfacing welding temperature is high and more alloy metal elements enter the bath. So column crystal particle disappears and more martensite is produced showing big particle and high hardness.

\subsection{Bending property test and analysis}

The bending test is carried out in the universal material testing machine to measure influence of deposited metal to bending strength of base metal, which can reflect the influence of deposited metal to quality of base metal as well. A little plastic deformation may damage the fragile material in bending test. So in the test, we made the specimen bent slightly and then observed if there was any crack or rupture. Because the block is not standard, we can't compare test data. We can only compare the bending strength of specimen A and B based on the pressure peak when specimen cracked. The data of bending test of specimen A and B conducted in the universal material testing machine are shown in table 3.

Tab.3 The bending test data of specimen

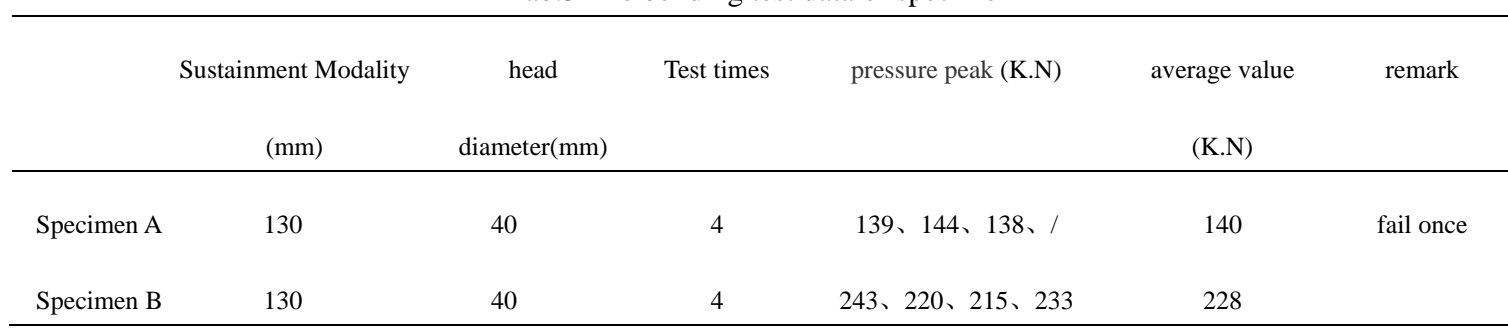

By comparing the data of the bending tests, we can know that pressure peak of crack of specimen B is significantly higher than A. The reason should be that dilution rate of powder-cored wire is high and the penetration ratio is big. So the hardness of the first layer of deposited metal is influenced by dilution effect of the base metal very much. When the welding is done with low 
welding energy input, melting of the carbide is not fully completed and the homogeneity of the austenite is poor. But the diffusion rate of the carbide alloying elements such as $\mathrm{Cr}, \mathrm{Mo}$, $\mathrm{V}$, etc. is originally small. Their slow diffusion also hinder the diffusion of $\mathrm{C}$. During the post welding cooling process, there even appears some welding flaw and reduces the bending strength of the base metal.

\section{Conclusion}

(1)The microstructure indicates that martensite in deposited metal of specimen B is finer and more uniformly distributed.

(2)The average hardness of the deposited metal in specimen A is about 51HRC and the minimum hardness is $38 \mathrm{HRC}$, while for specimen $\mathrm{B}$, the average hardness of the deposited metal is about 52HRC, the minimum hardness is 45HRC and the maximum hardness is 62HRC. Average hardness of the deposited metal in specimen B is slightly higher than A.

(3)From the bending test data we can know that the crack pressure peak of specimen A is low and one test is invalid. The crack pressure peak of specimen B is significantly higher than A.

(4)Through microstructure and performance test analysis, it is concluded that surfacing welding process of specimen $\mathrm{B}$ is more reasonable.

\section{References:}

[1]Jiguo Shan, Zuyu Dong, Binshi Xu. Progress of surfacing welding process in China and its application in basic industry [J]. China Surface Engineering, 2002, 4, 57-58.

[2]Xinhong Wang. Surfacing welding of metal material [M]. Beijing: China Machine Press, 2008.

[3]Zengda Zou. Welding material, process and equipment manual [M]. Beijing: Chemical Industry Press, 2001. 